ouabain binding capacity of cells from patients with essential hypertension can increase during incubation in the absence of the inhibitor. We do not suggest that the serum inhibitor is solely responsible for the disorder of leucocyte transport of cations in essential hypertension. Our study does not exclude a deficiency of other, ouabain resistant, cation transport pumps in the leucocyte. Our findings show, however, that the leucocyte is a useful model for studying in vitro the defects of transmembrane cation transport in essential hypertension.

We are grateful for the advice of the late Dr R P S Edmondson of the department of renal medicine, Singapore General Hospital. We thank Ms $S$ B Yeo, Ms C S Hay, and Ms B E Peh for technical help. The experiments with British serum were carried out at the MRC clinical pharmacology unit, Oxford, when EAT was supported by the Wellcome Foundation and VMSO by a Commonwealth medical fellowship and the British Council. The remainder of the study was supported by the Hypertension Laboratory Fund of the National University of Singapore.

\section{References}

1 Edmondson RPS, Thomas RD, Hilton PJ, Patrick J, Jones NF. Abnormal leucocyte composition and sodium transport in essential hypertension. Lancet 1975;i:1003-5.
2 Ambrosioni E, Costa FV, Montebugnoli L, Tartagni F, Magnani B. Increased intra-lymphocytic sodium content in essential hypertension: an index of impaired $\mathrm{Na}{ }^{*}$ cellular metabolism. Clin Sci 1981;61:181-6.

3 Poston L, Sewell RB, W'ilkinson SP, et al. Evidence for a circulating sodium transport inhibitor in essential hypertension. Br.Med J 1981;282:847-9.

4 de W'ardener HE, MacGregor GA. Dahl's hypothesis that a saluretic substance may be responsible for a sustained rise in arterial pressure: its possible role in essential hypertension. Kidney Int $1980: 18: 1-9$

5 Poston L, Wilkinson S, Sewell RB, Williams R. Sodium transport during the natriuresis of volume expansion; a study using peripheral blood leucocytes. Clin Sci 1982:63:243-9.

6 Hamlvn JM, Ringel R, Schaeffer JS, et al. A circulating inhibitor of $\mathrm{N}_{\mathrm{a}}{ }^{\circ}+\mathrm{K} \cdot \mathrm{K}^{\cdot}$ ATPase associated with essential hypertension. Nature 1982;300:650-2.

7 Oh VMS, Taylor EA, Ding JL, Boon NA, Aronson JK, Grahame-Smith DG. Enhancement of specific $\left[{ }^{3} \mathrm{H}\right]$-ouabain binding and ouabain-sensitive ${ }^{86}$ rubidium uptake in intact human lymphocytes by a dialysable factor in human and fetal calf serum. Clin Sci in press

8 Boon NA, Oh VMS, Tavlor EA, Johansen T, Aronson JK, Grahame-Smith DG. Measurement of specific $\left[{ }^{3} \mathrm{H}\right]$-ouabain binding to different types of human leucocytes. $\mathrm{Br} f \mathrm{Clin}$ Pharmacol $1984 ; 18: 153-61$

9 Gheyouche R, Uzan A, Le Fur G, Corgier $\mathrm{M}$. Decrease in $\left[{ }^{3} \mathrm{H}\right]$-ouabain binding sites in heart and brain from spontaneously hypertensive rats. Experientia 1981;37:492-3.

10 Glynn IM. Karlish SJD. The sodium pump. Annu Rev Physiol 1975:37:15-55.

11 Heagerty AM, Milner M, Bing RF, Thurston H, Swales JD. Leucocvte membrane sodium transport in normotensive populations: dissociation of abnormalities of sodium efflux from transport in normotensive populations: dissod

12 Gray HH, Poston L, Hilton PJ, Smith SJ, Markandu ND, MacGregor GA. Reversal by verapamil of defect in sodium transport in leucocytes in essential hypertension. Br.Med f 1984;288:673-5. 13 Boon NA, Harper C, Aronson JK, Grahame-Smith DG. Cation transport functions in vitro in patients with untreated essential hypertension: a comparison of erythrocytes and leucocytes. Clin $S_{\text {ci }}$ 1985;68:511-5.

14 Phillips RJW, Robinson BF. The dilator response to $\mathrm{K}^{*}$ is reduced in the forearm resistance vessels of men with primary hypertension. Clin Sci 1984;66:237-9.

Accepted 14.11 arch 1986

\title{
Benign melanocytic naevi as a risk factor for malignant melanoma
}

\author{
A J SWERDLOW，J ENGLISH， R M MACKIE， C J O'DOHERTY， J A A HUNTER， J CLARK, \\ D J HOLE
}

\begin{abstract}
Examination of 180 patients with cutaneous malignant melanoma and 197 control patients in a case-control study showed that the risk of melanoma is strongly related to numbers of benign melanocytic naevi (moles). Some unusual features of naevi-a diameter exceeding $7 \mathrm{~mm}$, colour variation, and irregular lateral outline-also showed a strong association with the risk of melanoma, but the relation of numbers of naevi to risk was present even in the group of patients whose naevi had none of these unusual features. Biopsy of clinically atypical naevi from several of the patients at highest risk generally did not show
\end{abstract}

\section{University of Glasgow}

A J SWERDLOW, PHD, MFCM, senior lecturer, department of community medicine

J ENGLISH, MB, MRCP, registrar, department of dermatology

R M MACKIE, FRSE, FRCPATH, professor, department of dermatology

J CLARK, BSC, research assistant, department of community medicine

Department of Dermatology, University of Edinburgh

C J O'DOHERTY, MSC, MRCP, lecturer

J A A HUNTER, MD, FRCPED, professor

West of Scotland Cancer Surveillance Unit, Glasgow

D J HOLE, MSC, senior statistician

Correspondence to: $\operatorname{Dr}$ A J Swerdlow, Office of Population Censuses and Surveys, Kingsway, London WC2B 6JP. dysplastic histology. Thus a group of people at high risk of melanoma may be identified by using simple clinical assessment of naevi.

\section{Introduction}

The incidence of and mortality from malignant melanoma of the skin have been rising rapidly in white populations around the world for many years. The search for high risk groups and preventive measures has, therefore, become particularly important. People with fair skin, blue eves, and blond or red hair are at increased risk of melanoma, "but the risks associated with these characteristics are moderate and because the characteristics are common among white populations it is not a useful way to define a high risk group who might benefit from preventive measures.

A high risk of melanoma is reported in patients with multiple histologically dysplastic naevi who come from families in which at least two members have had melanoma. Such families are, however, rare and account for only a small proportion of people with melanoma. The risks of melanoma in others with dysplastic naevi and with clinically atypical naevi have not vet been quantified. Furthermore, clinical criteria that reliably identify histologically dysplastic naevi have not been clearly determined: clinically atypical naevi do not always show the histological features described as characteristic of dysplastic naevi.

Several recent case-control studies, whose cases were not selected because of familial melanoma, have found a raised risk of melanoma in people with increased numbers of naevi or large naevi. ${ }^{-10}$ The number of clinically atypical naevi, however, was not determined, nor were sites other than the arms and legs examined for moles; no 
data are available on the relation between the site of naevi and the risk and site of melanoma. We, therefore, analysed the risk of melanoma by number, type, and site of naevi in a case-control study conducted in Scotland. The study included a skin examination of the whole body of the subjects by trained dermatologists.

\section{Subjects and methods}

A stratum matched, case-control study was conducted in which patients with primary cutaneous malignant melanoma (in the age range 15-84) who presented between 1979 and 1984 to the university departments of dermatology in Glasgow and Edinburgh and the West of Scotland plastic surgery unit were studied. The controls were inpatients and outpatients in Glasgow and Edinburgh with a range of non-malignant diagnoses, excluding chronic diseases considered likely substantially to affect lifestyle. Data on a wide range of potential risk factors for melanoma were obtained from the cases and controls during 1983 and 1984 by interview, by physical examination, and from case notes at hospitals. Subjects were not informed of the topic of the study, and the questionnaire was constructed to give no obvious indication of it until the final questions. The only questions that mentioned melanoma were asked after all other questioning was completed, and the physical examination was conducted after the interview.

The interview included questions on hair and eve colour, skin type, exposure to sun and other ultraviolet radiation, and occupation. The physical examination included a count and examination of all lesions considered to be benign melanocytic naevi greater than $2 \mathrm{~mm}$ diameter on all body sites except the scalp (for which exact counting was impractical and only presence or absence was recorded) and the genitalia. A lesion was regarded as a naevus in the study if it was a brown lesion on the skin that was not obviously a freckle, lentigo, or basal cell papilloma. The presence of the following clinically unusual features of naevi was noted: diameter greater than $7 \mathrm{~mm}$; irregular, dappled pigmentation of the lesion; and an irregular lateral outline.

Analysis was by stratum matched logistic regression with stratum matching for age (five year age groups), sex, and city of treatment. ${ }^{1 i}$ Relative risks were estimated without adjustment, and also with adjustment for several risk factors other than naevi. Analyses were conducted for melanoma overall and for subdivisions of melanoma by skin site and histological subtype.

\section{Results}

The study included 180 patients with melanoma and 197 controls. One hundred and thirteen $(63 \%)$ of the patients with melanoma and $120(61 \%)$ of the controls were women. The commonest sites of melanoma in the cases were the legs in women $(71(63 \%))$ and the trunk in men $(23(34 \%))$. Of the patients with melanoma, $94(52 \%)$ had superficial spreading melanoma and $45(25 \%)$ nodular melanoma, with fewer having acral lentiginous melanoma $(18(10 \%))$ and lentigo maligna melanoma $(16(9 \%))$. The patients with melanoma were similar in distributions of sex, age, and histological type to all patients with melanoma in Scotland during 1979-84'2 (Scottish Melanoma Group, unpublished findings) except that in our patients the proportions aged 70 or more and with lentigo maligna melanoma were smaller $(12 \%(21)$ compared with $27 \%(444)$ and $9 \%$ (16) compared with $15 \%$ (247)) respectively. The controls had a wide range of conditions at admission, the most common being hypertension ( 55 patients), psoriasis (31), and fractures and dislocations (20). Altogether $214(82 \%)$ of the 262 examinations in Glasgow were conducted by one dermatologist (JE) and $103(90 \%)$ of the 115 examinations in Edinburgh by another (CJO'D), often with simultaneous examination of the subjects by the second dermatologist at the centre to improve validity.

The risk of melanoma was strongly related to total numbers of naevi of any size and also to total numbers of naevi greater than $7 \mathrm{~mm}$ in diameter (table I). In addition, large significant risks of melanoma were associated with the presence of naevi with colour variation or an irregular lateral edge. Adjustment for risk factors for melanoma other than naevi made little difference to the results (table I). In analyses confined to patients without any naevi larger than $7 \mathrm{~mm}$ in diameter or showing colour variation or irregular edge ( 109 cases, 173 controls) there remained a strong association of numbers of naevi with risk of melanoma (table I), although, especially for subjects with 50 or more naevi, the association was not as strong as that seen when all the subjects were studied.

Further analyses were conducted excluding the 77 controls with dermatological conditions in case these controls were atypical of the general population with respect to benign naevi. In fact, this exclusion made little difference to the risks found. Analyses were also conducted stratifying for place of residence as well as for place of treatment in case the use of hospital controls had led to selection bias for controls; this stratification made little difference to the results.

Risk was examined separately for naevi on various body sites and also for subdivisions of melanoma by histology and site. Substantial and significant raised risks of melanoma overall were found for naevi on the palms, soles,

\begin{tabular}{|c|c|c|c|c|c|}
\hline & $\begin{array}{l}\text { No }(\%) \text { of cases with } \\
\text { risk factor }\end{array}$ & $\begin{array}{c}\text { No }(\%) \text { of controls with } \\
\text { risk factor }\end{array}$ & $\begin{array}{l}\text { Unadjusted relative risk } \\
(95 \% \text { confidence limits })\end{array}$ & $\begin{array}{l}\text { Adjusted relative riskt } \\
95 \% \text { confidence limits }\end{array}$ & $\begin{array}{l}\text { Unadjusted relative risk among } \\
\text { people without any large naevi } \\
\text { or naevi with colour variation } \\
\text { or irregular edges } \\
95 \% \text { confidence limits }\end{array}$ \\
\hline \multicolumn{6}{|c|}{ Features of naevi over whole body } \\
\hline No of naevi: & & & & & \\
\hline $\begin{array}{l}0 \\
1-9\end{array}$ & $\begin{array}{l}24(13) \\
30(17)\end{array}$ & $\begin{array}{l}39(20) \\
91 \quad 46\end{array}$ & $\begin{array}{l}1.0 \\
0.9(0.4-2 \cdot 0)\end{array}$ & $\begin{array}{l}1.0 \\
0.8(0.3-1.9)\end{array}$ & $\begin{array}{l}1.0 \\
0.8(0.4-1.8)\end{array}$ \\
\hline $10-24$ & $39(22)$ & $37(19)$ & $\begin{array}{l}0.9(0 \cdot 4-2 \cdot 0) \\
4.4(2 \cdot 2-8 \cdot 9)\end{array}$ & $\begin{array}{l}0.8(0.3-1.9) \\
6.7(2 \cdot 6-17 \cdot 4)\end{array}$ & $\begin{array}{l}0.8(0.4-1 \cdot 8) \\
3.0(1 \cdot 3-6.8)\end{array}$ \\
\hline $25-49$ & $32(18)$ & $21(11)$ & $8 \cdot 7(3 \cdot 6-20 \cdot 9)$ & $10 \cdot 7(4 \cdot 1-28 \cdot 3)$ & $6 \cdot 8(2 \cdot 7-17 \cdot 1)$ \\
\hline$\geqslant 50$ & $55(31)$ & $9(5)$ & $63 \cdot 8(19 \cdot 4-209 \cdot 4)$ & $53 \cdot 9(18 \cdot 3-158 \cdot 9)$ & $12 \cdot 1(2 \cdot 7-53 \cdot 9)$ \\
\hline \multicolumn{6}{|l|}{ No of large naevi: } \\
\hline 0 & $123(68)$ & 176 & $1 \cdot 0$ & $1 \cdot 0$ & \\
\hline $1-4$ & $44(24)$ & $18 \quad 9)$ & $5 \cdot 1(2 \cdot 5-10 \cdot 5)$ & $5 \cdot 2(2 \cdot 5-10 \cdot 8)$ & \\
\hline$\geqslant 5$ & $13(7)$ & $3(2)$ & $6 \cdot 0(1 \cdot 6-21 \cdot 9)$ & $5 \cdot 7(1 \cdot 5-21 \cdot 3)$ & \\
\hline Colour variation & $43(24)$ & $3(2)$ & $29 \cdot 6(7 \cdot 0-125 \cdot 6)$ & $29 \cdot 7(7 \cdot 0-125 \cdot 3)$ & \\
\hline Irregular edge & $50(28)$ & 21 & $72 \cdot 7(9 \cdot 7-542 \cdot 7)$ & $70 \cdot 4(9 \cdot 6-517 \cdot 8)$ & \\
\hline \multicolumn{6}{|c|}{ Site specific numbers of naevi } \\
\hline Scalp $(\geqslant 1)$ & $13(7)$ & +2 & $3 \cdot 9(1 \cdot 2 \cdot 12 \cdot 7)$ & $3 \cdot 4(1 \cdot 0-11 \cdot 4)$ & $1 \cdot 3(0 \cdot 2-10 \cdot 2)$ \\
\hline Neck $(\geqslant 1)$ & $52(29)$ & $37(19)$ & $2 \cdot 0(1 \cdot 2-3 \cdot 5)$ & $2 \cdot 1(1 \cdot 2-3 \cdot 6)$ & $1 \cdot 8(0 \cdot 9-3 \cdot 6)$ \\
\hline Face $(\geqslant 1)$ & $60(33)$ & 5628 & $1 \cdot 4(0 \cdot 9 \cdot 2 \cdot 2)$ & $1.5(0.9-2 \cdot 4)$ & $1 \cdot 0(0 \cdot 6-1 \cdot 9)$ \\
\hline Palm $(\geqslant 1)$ & 158 & $5 \quad 2$ & $3 \cdot 2(1 \cdot 1-8 \cdot 9$ & $3 \cdot 2 \cdot 1 \cdot 1-9 \cdot 2$ & $1 \cdot 2(0 \cdot 2-6 \cdot 2)$ \\
\hline Sole $(\geqslant 1)$ & $26(14)$ & 74 & $4.6(1 \cdot 9-11 \cdot 1)$ & $4 \cdot 2(1 \cdot 7-10 \cdot 3)$ & $6 \cdot 3(1 \cdot 7-23 \cdot 5)$ \\
\hline \multicolumn{6}{|l|}{ Trunk: } \\
\hline 0 & $4927)$ & $78+0$ & $1 \cdot 0$ & 1.0 & 1.0 \\
\hline $1-9$ & $74(41)$ & $109: 55$ & $1.50 .9-2 \cdot 7$ & $1.5(0.8-2 \cdot 6)$ & $1 \cdot 2(0 \cdot 7-2 \cdot 2)$ \\
\hline$\geqslant 10$ & $57(32)$ & $10 \quad 5$ & $21 \cdot 3(7 \cdot 9-57 \cdot 8)$ & $22 \cdot 5(8 \cdot 2-62 \cdot 1)$ & $9 \cdot 7(2 \cdot 4-38 \cdot 2)$ \\
\hline \multicolumn{6}{|l|}{ Arms: } \\
\hline 0 & +24 & $71: 36$ & 1.0 & 1.0 & 1.0 \\
\hline $1-9$ & $65(36)$ & 98,50 & $1 \cdot 7(1 \cdot 0-3 \cdot 0$ & $1 \cdot 8(1 \cdot 0-3 \cdot 3$ & $1 \cdot 2(0 \cdot 7-2 \cdot 2)$ \\
\hline$\geqslant 10$ & $71(39)$ & 2814 & $10 \cdot 2+8-21 \cdot 9$ & $14 \cdot 3(6 \cdot 5-31 \cdot 3$ & $4 \cdot 4 \cdot 9-10 \cdot 5)$ \\
\hline \multicolumn{6}{|l|}{ Legs: } \\
\hline 0 & $+0(22)$ & 8945 & $1 \cdot 0$ & $1 \cdot 0$ & $1 \cdot 0$ \\
\hline $1-9$ & $68(38)$ & $88+5$ & $3+1 \cdot 9-6 \cdot 3$ & $3.51 .9-6.5$ & $2 \cdot 3 \cdot 1 \cdot 2-4 \cdot 4$ \\
\hline$\geqslant 10$ & $72+0$ & 2010 & $42 \cdot 3,15 \cdot 6-114 \cdot 7$ & $48 \cdot 2(17 \cdot 2-135 \cdot 0$ & $10 \cdot 6 \cdot 3 \cdot 6-31 \cdot 1$ \\
\hline
\end{tabular}

^Based on all cases and controls for whom information was recorded the numbers of cases and controls underlying the calculations of relative risk are sometimes fewer because strata containing no cases or no controls could not be analysed, and in the final column because of exclusions; 
scalp, arms, legs, and trunk, with a strong dose response relation for each of these sites when there were sufficient people with several moles on the site for analysis (table I). The presence of naevi on the neck and face was a weaker risk factor. Table II shows the risk of melanoma in relation to histological type; adjustment for risk factors for melanoma other than naevi did not alter these results materially. Risks of superficial spreading melanoma and nodular melanoma were strongly and often significantly related to features of claimed that their melanoma had arisen in a pre-existing mole. In each sex melanoma of the trunk was the site most commonly thought to have arisen from a naevus ( $10(56 \%)$ of such melanomas in men, $12(92 \%)$ in women $)$; the histological type most often reported to have arisen from naevi was nodular melanoma in men (eight $(67 \%)$ ) and superficial spreading melanoma in women $(44(75 \%))$. The cause of any scars found at examination was sought: cosmetic excision of a naevus was not a common cause.

TABLE II-Relative risks of cutaneous melanoma and $95 \%$ confidence limits by histology for various aspects of benign melanocytic naevi

\begin{tabular}{|c|c|c|c|c|}
\hline & $\begin{array}{l}\text { Superficial spreading melanoma } \\
\qquad \mathrm{n}=94\end{array}$ & $\begin{array}{c}\text { Nodular melanoma } \\
\qquad n=4+\end{array}$ & $\begin{array}{l}\text { Lentigo maligna melanoma } \\
\qquad n=16\end{array}$ & $\begin{array}{l}\text { Acral lentiginous melanoma } \\
\qquad \mathrm{n}=18\end{array}$ \\
\hline \multicolumn{5}{|c|}{ Features of naect ocer whole body } \\
\hline \multicolumn{5}{|l|}{ No of naevi: } \\
\hline 0 & $1 \cdot 0$ & $1 \cdot 0$ & $1 \cdot 0$ & $1 \cdot 0$ \\
\hline $1-9$ & $0.5: 0 \cdot 1-1.7$ & $1 \cdot 1: 0 \cdot 3-4 \cdot 4$ & $2 \cdot 50 \cdot 4-14 \cdot 9$ & $1 \cdot 10.3-4 \cdot 8$ \\
\hline $10-24$ & $+01 \cdot 3-11 \cdot 8$ & $5 \cdot 1 \cdot 1 \cdot 7-15 \cdot 1$ & & $4 \cdot 2(0.8-21 \cdot 1)$ \\
\hline $\begin{array}{l}25-49 \\
\geqslant 50\end{array}$ & $\begin{array}{l}11 \cdot 8 \cdot 2 \cdot 9 \cdot 48 \cdot 6 \\
65 \cdot 9 \cdot 19 \cdot 5-222 \cdot 5\end{array}$ & $\begin{array}{ll}1+6 & 3 \cdot 5-60 \cdot 6 \\
+0 \cdot 1 & 9 \cdot 0-179 \cdot 3\end{array}$ & $1+\cdot 3 \cdot 1 \cdot 9-106 \cdot 1^{\star}$ & $3.9(0.4-43 \cdot 1$ \\
\hline \multicolumn{5}{|l|}{ No of large naevi: } \\
\hline 0 & $1 \cdot 0$ & $1 \cdot 0$ & $1 \cdot 0$ & 1.0 \\
\hline $\begin{array}{l}1-4 \\
\geqslant 5\end{array}$ & $\begin{array}{l}5 \cdot+2 \cdot 3-12 \cdot 6 \\
8 \cdot 9 \cdot 2 \cdot 3-35 \cdot 6\end{array}$ & \begin{tabular}{l:l|}
$3 \cdot 9$ & $1 \cdot 6 \cdot 9 \cdot 4$ \\
$6 \cdot 1$ & $0 \cdot 9-41 \cdot 6$
\end{tabular} & $3.8: 0.8-18.7$ * & $3 \cdot 00 \cdot 7-13 \cdot 8$ * \\
\hline Colour variation & $8,-3+5=0$ & $15 \cdot 73 \cdot 2-76 \cdot 6$ & + & + \\
\hline \multirow[t]{2}{*}{ Irregular edge } & $73 \cdot 8: 10 \cdot 0-546 \cdot 3$ & $73 \cdot 08 \cdot 9-560 \cdot 0$ & $t$ & $11 \cdot 6: 0 \cdot 8-160 \cdot 2$ \\
\hline & \multicolumn{4}{|c|}{ Sile specific numbers of naevi } \\
\hline Scalp $\geqslant 1$ & $4 \cdot 8: 1 \cdot 3-18 \cdot 1$ & $3 \cdot 2 \cdot 0 \cdot 3-37 \cdot 8$ & $t$ & $2 \cdot 8 \cdot 0 \cdot 2-47 \cdot 2$ \\
\hline Neck $\geqslant 1$ & $2 \cdot 1 \cdot 1 \cdot 1-3 \cdot 9$ & $2 \cdot 1 \cdot 0.8-5 \cdot 4$ & $1 \cdot 3 \cdot 0 \cdot 1-13 \cdot 1$ & $2 \cdot 4 \div 0.6-9 \cdot 8$ \\
\hline Face $\geqslant 1$ & $1 \cdot 4=0.8-2 \cdot 4$ & $1 \cdot 1 \quad 0 \cdot 5-2 \cdot 3$ & $6 \cdot 1 \cdot 1 \cdot 1-35 \cdot 5$ & $0 \cdot 8 \cdot 0 \cdot 2-3 \cdot 5$ \\
\hline Palm $(\geqslant 1)$ & $3 \cdot 7 \cdot 1 \cdot 2-11 \cdot 4$ & $2 \cdot 5 \quad 0 \cdot 5-13 \cdot 5$ & + & $t$ \\
\hline Sole $\geqslant 1$ & $4 \cdot 51 \cdot 6-12 \cdot 2$ & $11 \cdot 0 / 2 \cdot 1-57 \cdot 7$ & $3 \cdot 9 \cdot 0 \cdot 2-63 \cdot 3$ & $t$ \\
\hline \multicolumn{5}{|l|}{ Trunk: } \\
\hline 0 & $1 \cdot 0$ & $1 \cdot 0$ & $1 \cdot 0$ & $1 \cdot 0$ \\
\hline $1-9$ & $1.5,0.7-3.0$ & $1 \cdot 6: 0 \cdot 6-4 \cdot 2$ & $6.6,1.235 .2 *$ & $\mid 1 \cdot 2<0 \cdot 3-4 \cdot 4\}$ \\
\hline$\geqslant 10$ & $25 \cdot 17 \cdot+\cdot 84 \cdot 5$ & $28 \cdot 6 \quad 6 \cdot 7-122 \cdot 2 \cdot$ & $6 \cdot 6 \backslash 1 \cdot 2-35 \cdot 3 \star$ & $\{7 \cdot 1,0 \cdot 5-94 \cdot 5$ \\
\hline \multicolumn{5}{|l|}{ Arms: } \\
\hline 0 & $1 \cdot 0$ & 1.0 & 1.0 & $1 \cdot 0$ \\
\hline $1-9$ & $1.610 .8-3.5$ & $2 \cdot 3 \cdot 0 \cdot 9-5 \cdot 8$ & $6 \cdot 7: 1 \cdot 1-40 \cdot 2:$ & $1.1 .0 .3 .3 .1 *$ \\
\hline$\geqslant 10$ & $18 \cdot 0 \cdot 6 \cdot 6-49 \cdot 1$ & $8 \cdot 0 \cdot 2 \cdot 3-27 \cdot 7$ & $33 \cdot 81 \cdot 8-651 \cdot 6$ & $1 \cdot 1(0.3-3 \cdot 4)^{\star}$ \\
\hline \multicolumn{5}{|c|}{$35.8 \div 8-6310$} \\
\hline 0 & 1.0 & $1 \cdot 0$ & $1 \cdot 0$ & $1 \cdot 0$ \\
\hline $1-9$ & $+9 \cdot 2 \cdot 1-11 \cdot 7$ & $+7 \cdot 1 \cdot 7-12 \cdot 7$ & $4.50 .8-24.9 \star$ & $2 \cdot 3(0.6-8 \cdot 8$ * \\
\hline$\geqslant 10$ & $71 \cdot 8: 20 \cdot 8-2+8 \cdot 1$ & $40 \cdot 18 \cdot 5-188 \cdot 9$ & & \\
\hline
\end{tabular}

*Categories were combined ad hoc because the iterative estimation of the parameters would not converge for each category separately. tRelative risk could not be calculated because of instability of estimates and lack of convergence of the model or absence of cases or controls in the strata
used.

naevi over the whole body (that is, numbers of naevi, numbers of large naevi, colour variation, and irregular lateral outline) and to counts of naevi at each site, except on the neck and face for which the risks were less strong. Although analyses for lentigo maligna melanoma and acral lentiginous melanoma were based on small numbers of cases, they indicated, significantly in some instances for lentigo maligna melanoma but less clearly for acral lentiginous melanoma, that these histological types also were associated with the presence and appearance of naevi, although less strongly than were superficial spreading melanoma and nodular melanoma.

Large numbers and unusual clinical characteristics of benign naevi were risk factors for melanoma at each site analysed in the study (head and neck, trunk, arms, and legs) (table III). The risks were little altered by adjustment for risk factors for melanoma other than naevi. There were strong dose response relations in each analysis for which sufficient data were available to examine this. The site of melanoma showing the strongest association with most of the features of naevi was the trunk; the leg was usually the least strongly associated site. As in the analysis for melanoma overall, site specific risks of melanoma were generally lower for naevi on the face or neck than for naevi elsewhere. There was no clear evidence that the risk of melanoma at a particular site was more strongly related to numbers of naevi at that site than to numbers of naevi elsewhere.

To obtain a pathological diagnosis of pigmented naevi that were clinically unusual with regard to size, distribution of melanin pigment within the lesion, and irregular lateral margin we obtained biopsy specimens from 13 such lesions from nine patients. Ten of these lesions were benign compound melanocytic naevi with none of the features considered diagnostic of "dysplastic" naevi. Two naevi showed a minor degree of lentiginous and melanocytic hyperplasia, with occasional cytological atypia of individual melanocytes, and one naevus showed architectural atypia with hyperplasia of rete pegs and eosinophilic fibroplasia of the papillary dermis in addition to minor atypia of individual melanocytes.

No patients in the study had melanoma arising in a congenital naevus over $20 \mathrm{~cm}$ in largest diameter (giant or garment naevus). Of the 162 patients for whom data were available, $98(60 \%)(27(50 \%)$ men, $71(66 \%)$ women $)$

\section{Discussion}

This study shows that large numbers of benign melanocytic naevi are one of the strongest risk factors yet identified for malignant melanoma. Moles that are clinically unusual with regard to size, shape, or colour but are not histologically dysplastic are also strongly associated with risk of the tumour. Several of the relative risks found were large and unlikely to have occurred by chance. Many had not been investigated before, but our confidence that they were not an artefact is enhanced by the similarity of our results for associations previously investigated to those of other studies. Thus in studies of naevi on the arms and legs a raised risk has been found for large numbers of naevi $i^{7.9}$ and a greater risk has been found for superficial spreading melanoma and nodular melanoma than for lentigo maligna melanoma. ${ }^{8}$ The shape of the dose-response relation in our study was similar to that found by Holman and Armstrong, ${ }^{8}$ although different from that shown by Green et al. ${ }^{9}$ Information obtained in case-control studies asking patients about their naevi has also been compatible with the present findings, although interviews are an unsatisfactory source of such data..$^{70}$

The results reported here are unlikely to be explained by potential biases or other methodological artefacts, although these merit consideration. The interviewers and examiners knew whether the subject was a case or control and the site of melanoma, and thus observer bias was possible. This lack of blindness is virtually inevitable for whole body examinations. It seems unlikely, however, that unconscious bias could explain results of the magnitude of many of those found, and the findings specific to site and histology had a clear pattern that was not obviously the result of bias. The results cannot have been greatly affected by observer variation between centres, as the analyses were all stratified by centre, or by 
variation within observers within centres, as at each centre over $80 \%$ of the examinations were by the same observer. Nevertheless, great efforts were made to avoid such variation. Repeat counts of naevi on the same patient by different observers at the same centre, and by the same observer on two occasions, for a sample of patients including some for whom the second count was inadvertent and not known by the observer to be a repetition showed only minor variation within and between observers.

The use of hospital sources of cases for the study and the inclusion of cases who had presented before data collection began raised the possibility of selection bias. Comparison with all cases incident in Scotland over the period 1979-84 suggested, however, that the only selection bias was a loss of elderly patients with melanoma, mainly with lentigo maligna melanoma. This may be because some of these that they had "no moles." histologically melanocytic naevi the commonest cause of confusion? is the lentigo, in which there is a proliferation of rete pegs and an尺 increase of melanocytes in the basal layer. As these lesions arec generally $2 \mathrm{~mm}$ or less in diameter we counted only lesions greaterō than $2 \mathrm{~mm}$ in diameter in order to exclude most lentigines.

There is strong evidence that people with histologically dysplastic naevi who come from families in which two or more members have already developed melanoma are at high risk of melanoma. ${ }^{+}$There is currently considerable interest in the possibility of a raised risk of:melanoma in people who have dysplastic naevi but no family history $\overrightarrow{\vec{s}}$ of malignant melanoma (the so called sporadic dysplastic naevus ${ }_{0}^{+}$ syndrome). We would emphasise that moles that are clinicallye unusual in terms of large size, colour variation, and an irregularo

TABLE III-Relative risks of cutaneous melanoma and $95 \%$ confidence limits by site for various aspects of benign melanocytic naevi

\begin{tabular}{|c|c|c|c|c|}
\hline & $\begin{array}{l}\text { Legs } \\
\mathrm{n}=92\end{array}$ & $\begin{array}{l}\text { Trunk } \\
\mathrm{n}=37\end{array}$ & $\begin{array}{l}\text { Head and neck } \\
\qquad n=23\end{array}$ & $\begin{array}{l}\text { Arms } \\
\mathrm{n}=22\end{array}$ \\
\hline \multicolumn{5}{|c|}{ Features of naevi ower whole body } \\
\hline \multicolumn{5}{|l|}{ No of naevi: } \\
\hline $\begin{array}{l}0 \\
1-9\end{array}$ & $\begin{array}{ll}1 \cdot 0 & 1 \\
0 \cdot 8 & 0 \cdot 3-2 \cdot 2\end{array}$ & $1 \cdot 0^{\star}$ & $1 \cdot 0^{\star}$ & $1 \cdot 0^{\star}$ \\
\hline $10-24$ & $3 \cdot 2 \cdot 1 \cdot 3-8 \cdot 2$ & $27 \cdot 0,3 \cdot 1-228 \cdot 9$ & & $2 \cdot 5(0.5-13 \cdot 3)$ \\
\hline $\left.\begin{array}{l}25.49 \\
\geqslant 50\end{array}\right\}$ & $10 \cdot 5+0-27 \cdot 7$ ฝ & $239 \cdot 0(22 \cdot 6-2526 \cdot 0 \star\}$ & $11 \cdot 1(2 \cdot 2-56 \cdot 9) \star$ & $20 \cdot 7(3 \cdot 9-109 \cdot 8)^{\star}$ \\
\hline \multicolumn{5}{|l|}{ No of large naevi: } \\
\hline 0 & $1 \cdot 0$ & $1 \cdot 0$ & $1 \cdot 0$ & $1 \cdot 0$ \\
\hline $\left.\begin{array}{r}1-4 \\
\geqslant 5\end{array}\right\}$ & $3 \cdot 6\left(1 \cdot 6-8 \cdot 0{ }^{\star}\right.$ & $10 \cdot 03.3-30.6 \star$ & $13 \cdot 0(2 \cdot 7 \cdot 62 \cdot 2)^{\star}$ & $7 \cdot 4(1 \cdot 8-30 \cdot 4)^{\star}$ \\
\hline Colour variation in naevi & $24 \cdot 53 \cdot 2-189 \cdot 3$ & $t$ & $20 \cdot 5(2 \cdot 4-178 \cdot 0)$ & $t$ \\
\hline Irregular edge to naevi & $33 \cdot 3(4 \cdot 4-252 \cdot 3)$ & $61 \cdot 5(7 \cdot 6-496 \cdot 1)$ & $t$ & $t$ \\
\hline \multicolumn{5}{|c|}{ Site specific numbers of naevi } \\
\hline Scalp $(\geqslant 1)$ & $1 \cdot 7(0 \cdot 4-6 \cdot 8$ & $15 \cdot 2(1 \cdot 8-131 \cdot 5)$ & $9 \cdot 9(0.9-110 \cdot 1)$ & $t$ \\
\hline $\operatorname{Neck}(\geqslant 1)$ & $1.6(0.8-3 \cdot 0$ & $2 \cdot 91 \cdot 2-7 \cdot 4$ & $1 \cdot 7(0 \cdot 5-6 \cdot 1)$ & $3 \cdot 6(1 \cdot 1-12 \cdot 1)$ \\
\hline Face $(\geqslant 1)$ & $1 \cdot 3(0.7-2 \cdot 4)$ & $1 \cdot 3(0.6-2 \cdot 9)$ & $3 \cdot 0(0 \cdot 9-9 \cdot 6)$ & $1 \cdot 1(0.4-3 \cdot 0)$ \\
\hline Palm $(\geqslant 1)$ & $3 \cdot 8(1 \cdot 2-12 \cdot 5)$ & $4 \cdot 2(0 \cdot 9-19 \cdot 6)$ & $1 \cdot 2(0 \cdot 1-14 \cdot 4)$ & $t$ \\
\hline Sole $(\geqslant 1)$ & $5.3(1.9-15 \cdot 0)$ & $29 \cdot 4(3 \cdot 5-244 \cdot 6)$ & $2 \cdot 2(0 \cdot 2-25 \cdot 0)$ & $t$ \\
\hline \multicolumn{5}{|l|}{ Trunk: } \\
\hline 0 & 1.0 & $1 \cdot 0$ & $1 \cdot 0$ & $1 \cdot 0$ \\
\hline $1-9$ & $0.9(0.5-1.8)$ & $5 \cdot 4(1 \cdot 1-27 \cdot 1)$ & $5 \cdot 4(1 \cdot 3-22 \cdot 2)$ & $1 \cdot 5(0 \cdot 4-6 \cdot 3)$ \\
\hline$\geqslant 10$ & $8 \cdot 3(2 \cdot 5-28 \cdot 2)$ & $279 \cdot 9(22 \cdot 8-3429 \cdot 5)$ & $83 \cdot 1(6 \cdot 2-1109 \cdot 4)$ & $38 \cdot 6(3 \cdot 6-410 \cdot 6)$ \\
\hline \multicolumn{5}{|l|}{ Arms: } \\
\hline 0 & $1 \cdot 0$ & $1 \cdot 0$ & 1.0 & $1 \cdot 0$ \\
\hline $1-9$ & $1 \cdot 0(0.5-2 \cdot 0)$ & $18 \cdot 2(1 \cdot 8 \cdot 181 \cdot 8)$ & $9 \cdot 2(1 \cdot 7-50 \cdot 3)$ & $1 \cdot 3(0 \cdot 3-5 \cdot 0)$ \\
\hline$\geqslant 10$ & $3 \cdot 9(1 \cdot 5-10 \cdot 1)$ & $246 \cdot 2(19 \cdot 1-3166 \cdot 0)$ & $79 \cdot 7(5 \cdot 2-1213 \cdot 8)$ & $14 \cdot 7(2 \cdot 3 \cdot 94 \cdot 5)$ \\
\hline \multicolumn{5}{|c|}{ 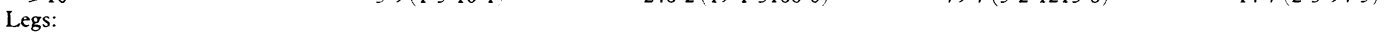 } \\
\hline 0 & $1 \cdot 0$ & $1 \cdot 0$ & $1 \cdot 0$ & $1 \cdot 0$ \\
\hline $1-9$ & $3 \cdot 4(1 \cdot 5-7 \cdot 4)$ & $21 \cdot 3(2 \cdot 7-167 \cdot 1)$ & $4 \cdot 2(1 \cdot 0-17 \cdot 4)$ & $1 \cdot 2(0 \cdot 2-5 \cdot 6)$ \\
\hline$\geqslant 10$ & $30 \cdot 6(8 \cdot 9-105 \cdot 5)$ & $629 \cdot 8(36 \cdot 3-10919 \cdot 3)$ & $26 \cdot 0(3 \cdot 3-203 \cdot 0)$ & $39 \cdot 3(3 \cdot 8-412 \cdot 8)$ \\
\hline
\end{tabular}

*Categories were combined ad hoc because the iterative estimation of the parameters would not converge for each category separately.

tRelative risk could not be calculated because of instability of estimates and lack of convergence of the model or absence of cases or controls in the strata used.

patients were too frail to travel for interview or had died of other causes before interview was possible. Overall, case selection does not appear to have been substantial and it seems unlikely that it biased appreciably the numbers of benign naevi in the cases as the number of naevi is not a criterion used in selecting mode or place of treatment, nor is it known to be associated with any factors influencing type or place of treatment. In confirmation of this there were similar proportions of patients with high numbers of naevi among the cases from each of the two hospitals covering roughly the same west of Scotland catchment area.

The results of the analyses adjusting for known risk factors other than naevi suggested that, as in previous work, ${ }^{89}$ there was no major confounding by these factors. If unknown risk factors were confounders it would be important to find them: for such factors to explain the findings they would need to be greater risk factors for melanoma than are naevi. ${ }^{13}$

Interpretation of the relation between naevi and melanoma is critically dependent on the definitions and the methods of measurement used for naevi. "Mole" counts carried out by patients themselves, or patients' comments on whether they have a "normal" number of "moles," are clearly unsatisfactory. In a recent study of normal subjects many subjects who were found by trained dermatologists to have more than 20 naevi stated, when first approached, lateral edge do not all have the pathological features of dysplastico naevi as defined by Elder et $a l^{t}$; many such lesions have the histological features of common compound naevi. ${ }^{5}$ This was true for 10 lesions from which biopsy specimens were obtained in our study N Our results suggest that the high risk of melanoma in relation to naevi may be identified by simple clinical measures withouto histological examination and that the degree of risk forms continuum rather than a dichotomy.

Several possible mechanisms might account for an association $N^{2}$ between large numbers of naevi and a raised risk of melanoma? People with many benign naevi almost certainly have moreo cutaneous "naevomelanocytes" and may have in total more melanocytes at risk of malignancy than people with few naevi. They ${ }^{+}$ may have melanocytes that are individually more susceptible to malignancy than the melanocytes of people with few naevi; or the clusters of naevomelanocytes within naevi may be at greater risk of malignancy than melanocytes elsewhere in the skin, and hence people with more naevi may have more clusters of cells at high risk of malignancy. In the first two instances (that is, greater numbers or greater susceptibility of melanocytes in the skin, or both) the presence of large numbers of moles would be an indicator of high risk of melanoma rather than itself be a cause of melanoma. Many moles might indicate a genetic tendency to formation of large 
BRTISH MEDICAL JOURNAL VOLUME 29214 JUNE 1986

numbers of moles and to formation of high risk melanocytes or might indicate that prior exposure to an environmental agentfor example, perhaps the sun-caused independently both large numbers of moles and malignancy. The third potential mechanism-that the melanocytes in naevi are particularly prone to melanoma-is supported at least partially by the finding in pathological studies that in $20 \%$ or more of melanomas malignant melanocytes can be identified histologically in contiguity with benign naevus cells. ${ }^{15}$ In clinical studies a large proportion of patients with melanoma give a history of an antecedent pigmented lesion at the site of their melanoma, ${ }^{15}$ but these studies give weak evidence because there is great potential for misunderstanding (as patients may mistake the early stages of superficial spreading melanoma or lentigo maligna melanoma for a mole) and for bias.

The histology and the site, which in our study and another were most highly associated with naevi, ${ }^{8}$ were also those for which in other publications the greatest proportion of melanomas have been identified histologically in contiguity with benign naevus cells-namely, superficial spreading melanoma ${ }^{16-18}$ and trunk melanomas. ${ }^{16} 17$ These were also the histological type and site for which the greatest proportion of patients in the present study gave a history of an antecedent "mole" at the site of their melanoma, although, as noted above, these histories give weak evidence. The findings by histological type are in a direction compatible with the hypothesis that naevi are precursors of superficial spreading melanoma and nodular melanoma but not lentigo maligna melanoma ${ }^{19}$; this hypothesis is supported by ultrastructural evidence, ${ }^{20}$ but the epidemiological evidence is also compatible with other hypotheses.

In conclusion, we suggest that people with large numbers of benign melanocytic naevi, and those with clinically atypical but not necessarily histologically dysplastic naevi, are at greatly increased risk of melanoma. Such people should be warned about recognising early melanoma and avoiding risk factors and notably advised about exposure to ultraviolet radiation. The aetiology of benign melanocytic naevi needs investigation and may elucidate the aetiology of melanoma.

We thank the Greater Glasgow Health Board Research Support Group and Eli Lilly and Company for financial support, colleagues who allowed us to approach their patients, and the Scottish Melanoma Group for permission to refer to unpublished material.

\section{References}

1 Jensen OM, Bolander AM. Trends in malignant melanoma of the skin. World Health Stat $Q$ 1980;33:2-26.

2 Lee JAH. Melanoma and exposure to sunlight. Epidemiol Reo 1982;4:110-36.

3 Swerdlow AJ. Epidemiology of cutaneous malignant melanoma. In: MacKie RM, ed. Melanoma. (Clinics in Oncology. Vol 3. No 3.) London: W B Saunders, 1984:407-37.

4 Greene MH, Clark WH Jr, Tucker MA, et al. Acquired precursors of cutaneous malignant melanoma: the familial dysplastic nevus syndrome. N Engl J Med 1985;312:91-7.

5 Seywright MM, Doherty VR, MacKie RM. Proposed alternative terminology and subclassification of so called "dysplastic naevi." I Clin Pathol (in press).

6 Elder DE, Goldman LI, Goldman SC, Greene MH, Clark WH Jr. Dysplastic nevus syndrome: a phenotypic association of sporadic cutaneous melanoma. Cancer 1980;46:1787-94.

7 Beral V, Evans S, Shaw H, Milton G. Cutaneous factors related to the risk of malignant melanoma. Br J Dermatol 1983;109:165-72.

8 Holman CDJ, Armstrong BK. Pigmentary traits, ethnic origin, benign nevi, and family history as risk factors for cutaneous malignant melanoma. Joumal of the National Cancer Institute 1984;72:257-66

9 Green A, MacLennan R, Siskind V. Common acquired naevi and the risk of malignant melanoma. Int f Cancer 1985;35:297-300.

0 Reynolds $\mathrm{P}$, Austin $\mathrm{D}$, Thomas $\mathrm{J}$. Familial and occupational risks associated with malignant melanoma of the skin. Am $\mathcal{F}$ Epidemiol 1982;116:570.

11 Smith PG, Pike MC, Hill AP, Breslow NE, Day NE. Multivariate conditional logistic analysis of stratum-matched case-control studies. Applied Statistics 1981:30:190-7.

12 MacKie RM, Smyth JF, Soutar DS, et al. Malignant melanoma in Scotland 1979-83. Lancet 1985 ;ii:859-62.

13 Breslow NE, Day NE. Statistical methods in cancer research. The anatysis of case-control studies. Vol 1. Lyons: International Agency for Research on Cancer, 1980. (IARC Scientific Publications No 32.)

14 MacKie RM, English J, Aitchison TC, Fitzsimons CP, Wilson P. The number and distribution of benign pigmented moles (melanocytic naevi) in a healthy British population. $\mathrm{Br} \mathcal{J}$ Dermatol $1985 ; 113: 167-74$

15 Elder DE, Greene MH, Bondi EE, Clark WH Jr. Acquired melanocytic nevi and melanoma: the dysplastic nevus syndrome. In: Ackerman AB, ed. Pathology of matignant melanoma. New York: Masson, 1981:185-215.

16 Rippey JJ, Whiting DA. Moles and melanomas. Lancet 1977;ii:137.

17 Rhodes AR, Sober AJ, Day CL, et al. The malignant potential of small congenital nevocellular nevi. An estimate of association based on a histologic study of 234 primary cutaneous melanomas. $\mathcal{I}$ Am Acad Dermatol 1982;6:230-41.

18 Clark WH Jr, Elder DE, Guerry D IV, Epstein MN, Greene MH, Van Horn M. A study of tumor progression: the precursor lesions of superficial spreading and nodular melanoma. Hum Pathol 1984;15:1147-65.

19 Holman CDJ, Armstrong BK, Heenan PJ. A theory of the etiology and pathogenesis of human cutaneous malignant melanoma. Fournal of the National Cancer Institute 1983;71:651-6.

20 Mishima Y. Melanocytic and nevocytic malignant melanomas. Cellular and subcellular differentiation. Cancer 1967;20:632-49.

(Accepted I April 1986)

\section{Self poisoning with oral cadmium chloride}

Stress related to examinations is a frequent cause of self poisoning in teenagers and young adults. The agents used and amounts consumed are not usually dangerous, however, and thus the overall mortality and morbidity are low.

Deliberate self poisoning with cadmium is extremely rare, but we describe a case illustrating the severe metabolic sequelae and destruction of tissue that follow oral ingestion of cadmium chloride.

\section{Case report}

A 17 year old girl was admitted to hospital with facial swelling and vomiting. She had been fit and well earlier at school but on arrival at the accident and emergency department was too ill to provide any history. She had increasing facial, pharyngeal, and neck oedema and was hypotensive. A presumptive diagnosis of angioneurotic oedema was made, but she did not respond to steroids given intravenously and a histamine $\mathrm{H}_{1}$ receptor antagonist.

One hour after admission a bottle of cadmium chloride crystals, which haci been removed from the school laboratory reagent store, was found in her handbag. Subsequent gastric washout (roughly three hours after ingestion) produced white crystalline material, later confirmed to be cadmium chloride.

Her condition deteriorated rapidly. She suffered a respiratory arrest, requiring endotracheal intubation and mechanical ventilation. Despite treatment with edetic acid and colloid and crystalloid infusions, she continued to deteriorate, becoming hypothermic (temperature $30^{\circ} \mathrm{C}$ on a low reading thermometer), haemoconcentrated (haemoglobin $222 \mathrm{~g} / 1$, packed cell volume 0.52 ), glucose intolerant (glucose $55.8 \mathrm{mmol} / /(1004.4 \mathrm{~g} / 100 \mathrm{ml})$ ), and acidotic $(\mathrm{pH} 6.9)$ without ketones. Results of coagulation studies were severely deranged (prothrombin time 60 seconds, control 13 seconds; partial thromboplastin time 180 seconds, control 39 seconds)

Over 24 hours she developed pulmonary and generalised oedema and oliguria. Full supportive measures, chelation treatment, charcoal haemoperfusion, and positive end expiratory pressure ventilation were unsuccessful, and she died 30 hours after admission.

Necropsy showed pulmonary oedema, pleural effusions, and ascites. There was haemorrhagic necrosis of the stomach, duodenum, and jejunum, foca hepatic necrosis, and slight pancreatic haemorrhage. The kidneys appeared normal. Tissue, blood, and urinary cadmium concentrations were measured by atomic absorption spectrophotometry (Varian 475 spectrophotometer) and found to be considerably raised (blood cadmium $208 \mu \mathrm{mol} / 1(23 \mathrm{~g} / \mathrm{l})$, normal range $<89$ $\mathrm{nmol} / \mathrm{l}(10 \mu \mathrm{g} / \mathrm{l})$; urinary cadmium $153 \mu \mathrm{mol} / 1$ (17 $\mathrm{g} / \mathrm{l})$; liver cadmium 3.6 $\mathrm{nmol} / \mathrm{kg}(0.4 \mu \mathrm{g} / \mathrm{kg})$ wet tissue; lung cadmium $1.7 \mathrm{nmol} / \mathrm{kg}(0.2 \mu \mathrm{g} / \mathrm{kg})$ wet tissue).

\section{Comment}

In the United Kingdom we are not aware of any reported cases of cadmium used for self poisoning. Cadmium is strongly bound to a carrier protein metallothionine, has a long biological half life, and is widely distributed in the body, ${ }^{1}$ particularly the kidney, which contains one third of total body cadmium.

Smelters or welders accidentally exposed to high concentrations of cadmium develop the syndrome of "fume fever," characterised by cough, dyspnoea, and myalgia. After 24-48 hours pulmonary oedema develops, which may be fatal. Chronic exposure to low concentrations of cadmium usually results in renal tubular dysfunction, proteinuria, a fall in creatinine clearance, and a rise in urinary $\beta$ microglobulin. ${ }^{2}$ Other manifestations include osteomalacia, emphysema, and hypochromic anaemia. ${ }^{3}$ 